\title{
A RECEPÇÃO DE GRANDE SERTÃO: VEREDAS, DE GUIMARÃES ROSA, POR PAULO MENDES CAMPOS, NO CONTEXTO JORNALÍSTICO E DAS CRÔNICAS
}

\author{
COSTA, Fabrício Lemos da ${ }^{1}$ \\ HOLANDA, Sílvio Augusto de Oliveira ${ }^{2}$
}

RESUMO: Este artigo tem por objetivo refletir sobre a recepção de Grande sertão: veredas (1956), de Guimarães Rosa (1908-1967), por Paulo Mendes Campos (1922-1991), no contexto das crônicas, no qual chamaremos, neste trabalho, de "recepção de primeiras horas", feito em contexto de divulgação em periódico, na conhecida Revista Manchete, em 13 de Outubro de 1956, na Coluna "Conversa Literária", $n^{\circ}$ 234. Trata-se da crônica "Grande sertão: veredas (João Guimarães Rosa)" (1956). Ressaltaremos, nesta interpretação realizada no mesmo ano de publicação do romance, sua particularidade artística, assim como analisaremos sua leitura que enfatiza os elementos internos à narrativa de Guimarães Rosa, isto é, a interseção entre o universal e o moderno no pensamento do personagem Riobaldo. Além disso, para o comentário da leitura do romance rosiano por Campos, dialogaremos com outros intérpretes da obra do escritor mineiro, quanto ao que estamos considerando como primeira recepção, como Alvarenga (1956), Candido (1956 e 1957), Milliet (1959) e Proença (1958).

PALAVRAS-CHAVE: Grande sertão: veredas, Guimarães Rosa, Paulo Mendes Campos, Recepção, Crônica.

\section{THE RECEPTION OF GRANDE SERTÃO: VEREDAS, BY GUIMARÃES ROSA, BY PAULO MENDES CAMPO, IN THE JORNALISTIC AND CHRONICLES CONTEXT}

\footnotetext{
ABSTRACT: This article aims to reflect on the reception of Grande sertão: veredas (1956), by Guimarães Rosa (1908-1967), by Paulo Mendes Campos (1922-1991) in the chronicles context, in which we will call, in this article of "reception of first hours", made in the context of a periodical publication, in the well-known Manchete magazine, on October 13, 1956, in the "Conversa Literária"

${ }^{1}$ Mestre em Letras pela Universidade Federal do Pará.

${ }^{2}$ Doutor em Teoria Literária e Literatura Comparada pela USP. Professor Associado da Faculdade de Letras e do Programa de Pós-Graduação em Letras (PPGL) da Universidade Federal do Pará.

Jangada | nr. 16, jun/dez, 2020 | ISSN 2317-4722

188 | Pá g in a
} 


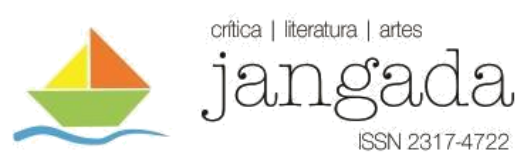

column, no 234. It's "Grande sertão: veredas (João Guimarães Rosa)" (1956) chronicle. We will emphasize, in this interpretation performed in the same year of publication of the novel, its artistic particularity, as well as we will analyze its reading that highlights the internal elements to Guimarães Rosa's narrative, that is the intersection between the universal and the modern in the thought of the character Riobaldo. Also, for commenting on Campos' reading of the rosiano novel, we will dialogue with other interpreters of the inhabitant of Minas Gerais writer's work, in what we are considering as the first reception, such as Alvarenga (1956), Candido (1956, 1957), Milliet (1959) and Proença (1958).

KEYWORDS: Grande sertão: veredas, Guimarães Rosa, Paulo Mendes Campos, Reception, Chronicle.

Porque um livro como esse é guardado para sempre; eu o louvo com modéstia e espanto. Paulo Mendes Campos, Manchete $^{3}$

Grande sertão: veredas, de Guimarães Rosa, foi publicado, pela primeira vez, em 1956. Assim, decorridas várias décadas de seu aparecimento, consideramos ainda fundamental a análise da recepção do que chamamos de "primeiras horas", isto é, interpretações realizadas e divulgadas no mesmo ano do surgimento da obra, em que o corpus deste trabalho está incluído. Trata-se da crônica “Grande sertão: veredas (João Guimarães Rosa)”, de Paulo Mendes Campos, que lê artisticamente o romance, àquela altura, pouco conhecido do grande público, em 1956.

Hoje, o romance é reconhecido e plenamente divulgado a um maior público, mas quando falamos "reconhecido", significa dizer um momento demarcado no tempo, no qual, requer uma investigação cuidadosa, pois nem sempre uma obra foi "bem admitida", sobretudo pela crítica especializada. Dessa maneira, sabedores de que, muitas vezes, a crítica não recebe, num primeiro momento, uma obra positivamente, ou o contrário, faz-se mister revisitarmos essas primeiras leituras e impressões do hoje lido, estudado e consagrado romance rosiano, mesmo em textos não classificados como críticos.

Para isto, desenvolveremos uma pesquisa e análise da recepção de Grande sertão: veredas, por Paulo Mendes Campos, publicada em 1956, pela “Coluna Conversa Literária”, da Revista Manchete ${ }^{4}$. Nela, tentaremos abordar dois matizes desta leitura: Na primeira, trata-se

\footnotetext{
${ }^{3}$ CAMPOS, 1956, p. 45.

${ }^{4}$ Cf. BEZERRA, 2015, p. 10: "Revista em que Paulo colaborou desde 1952, ano da fundação, quando estreou na coluna "Conversa Literária" com a crônica "Um fundador fiel", de 29 de novembro. Sua atuação nesse periódico
} 


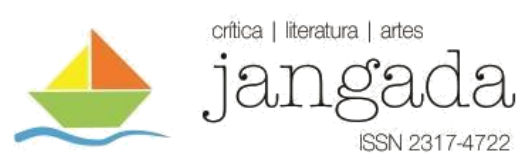

do caráter "modesto e de espanto", arrolado pela ausência de uma maior fortuna crítica do romance, do outro, a consciência de elementos por demais marcados mais tarde por reconhecidos intérpretes de Rosa: a presença do antigo e do moderno, já percebido pelo cronista Paulo Mendes Campos, embora sem compromisso com a argumentação e a objetividade, no modo como compreendemos o trabalho crítico, isto é, interessado na problematização de conceitos e comparações. Antes de apresentarmos a crônica, vale a pena mencionarmos uma breve biografia do cronista. Paulo Mendes Campos, natural de Belo Horizonte, pertenceu a uma geração de intelectuais mineiros, ficando mais conhecido no resto do Brasil a partir da década de 1960. Durante mais de 30 anos colaborou como cronista em vários periódicos brasileiros, entre eles, a Revista Manchete. Com Otto Lara Resende, Fernando Sabino e Hélio Pelegrino, formou o grupo “Apocalipse íntimo”.

Por se tratar de texto pouco conhecido ${ }^{5}$, trazemo-lo, aqui, na íntegra:

"Grande Sertão: Veredas"

(João Guimarães Rosa)

Porque êsse livro conta uma história que ainda não ouvíramos, que precisávamos ouvir, uma história que agora se torna impossível imaginar não existindo; porque devemos escutar uma história ao amanhecer, outra ao meiodia, outra ao cair da noite; uma história na infância, outra ao abrir-se das luzes e das sombras da maturidade, outra quando um farol no golfo escuro decidir

criado por Adolpho Bloch iria até 23 de agosto de 1975, dia em que publicou "Antônio Houaiss, o homemenciclopédia". Foram 23 anos seguidos de colaboração."

${ }^{5}$ Ao falarmos de texto "pouco conhecido", devemos esclarecer alguns pontos. A crônica de Paulo Mendes Campos foi publicada pela primeira vez pela Revista Manchete (1956). Em 1970, a Editora José Olympio publicou a primeira edição de Ave, Palavra, reeditando-o em 1978. Na contracapa, que se estende à orelha do livro, é inserida a crônica de Campos. Vale ressaltar que, curiosamente, o texto do cronista, como fica demonstrado em nosso trabalho, faz referência, exclusivamente, ao Grande sertão: veredas (1956). Acreditamos, pois, que ao incluir o texto de Campos, o editor e o organizador da obra póstuma, tinham como objetivo usá-la como um "convite" à leitura de toda a obra de Rosa, no qual Ave, Palavra faz parte. Assim, acrescentou-se o seguinte trecho na versão de 1970: "Vinte e três razões por que todos devem ler e é preciso louvar o livro de Guimarães Rosa". Por outro lado, outro aspecto "salta aos olhos" quando comparamos a publicação original daquela que aparece nas edições de 1970 e 1978, no chamado livro de "miscelânea". Ao sair do contexto jornalístico e das colunas da Revista Manchete para se tornar contracapa e orelha de livro, o texto passa por muitas mudanças. Vocábulos e trechos são trocados e retirados, como temos nos seguintes exemplos: "Grécia" por "Ageu", "cair da noite" por "boca da noite", "porque este livro repete" por "este livro reproduz", Riobaldo está a meu lado" por "Riobaldo está a teu lado", filosofia universal" por "religião universal", "porque essa obra de arte, generosa como a fertilidade do solo" por " esta obra de arte, doada como um fruto", "porque o ritmo é o comentário que o autor faz às suas palavras, sua personalidade" por "porque o ritmo é o comentário que faz o autor a suas palavras, suas orações". Por fim, em formato de caixa alta, ele acrescenta: "porque um livro como esse é guardado para sempre" por "NÓS RELEREMOS PARA SEMPRE UM LIVRO COMO ESTE”. Neste ínterim, não sabemos, ao certo, confirmar o real objetivo de todas estas mudanças, podendo ser por questões editoriais, ou ainda, de uma possível insatisfação do próprio cronista. De qualquer forma, nossa interpretação tem como base, unicamente, a primeira edição da Revista Manchete, aquela publicada poucos meses depois do aparecimento de Grande sertão. 
o caminho da velhice; porque há uma história no princípio, outra no meio, outra no fim do mundo; porque as três histórias são uma única história: os enredos do homem com sua força e seu mêdo, e a mulher com sua fragilidade e sua coragem; porque êsse livro repete a parábola da vida humana sôbre a terra e nos molha no frescor das primitivas vegetações terrestres até aclararnos ou ofuscar-nos em definitivas indagações da consciência; porque os homens são um único homem, e um único homem são todos os homens, porque Riobaldo estêve na Grécia, no castelo que preparava a guerra santa, na grande revolução libertária, no sertão de Minas entre os jagunços, e Riobaldo está a meu lado; porque a metafísica de Riobaldo percorre os tempos do mundo de ponta a ponta; porque Riobaldo é ação que se contempla e o pensamento que sai armado cavaleiro;

Porque a invenção dêsse livro é constante como os movimentos da natureza e as inquietações do pensamento, nessa reciprocidade que faz o homem patético perante as vagas do oceano, e fria e inapelável a órbita das êstrelas;

Porque filosofar é a solidão do homem anônimo e, no entanto, através da solidão êste anônimo comunga na filosofia universal; porque só o exercício do sofrimento pode abrir esperança ao pensamento de Riobaldo; e o pensamento de Riobaldo vai, perdido e achado, como um bando de homens armados através do sertão;

Porque essa obra de arte, generosa como a fertilidade do solo, indo não sei onde, onde quer que o espírito a leve, tem a armação matemática com que se desenhou a harmonia do templo em louvor de um espírito sem forma, além de todos os cálculos; porque sempre, acima da sintaxe estruturada, há-de soprar o vento do espírito - a fim de que as contradições do nosso destino se realizem;

Porque tôdas as partes dêsse livro cooperam entre si e aspiram a um fim; porque tôdas as suas figuras cooperam entre si e aspiram a um fim; porque seus hipérbatos, pleonasmos, anacolutos, anástrofes, idiotismos, prosopopéias, hipérboles, perífrases, metomínias, sinédoques, cooperam entre si e aspiram a um fim; e o fim a que aspiram é o entendimento e a denúncia dos homens; para que êstes não continuem matéria de escândalo mas ponto de partida à vida comum, o amor comum;

e ainda porque nesse livro se repetem a perplexidade das lendas mais antigas, o bem e o mal dos mais velhos humanismos; "eu careço de que o bom seja bom e o ruim ruim, que dum lado esteja o prêto e do outro o branco, que o feio 
fique bem apartado do bonito e a alegria longe da tristeza"; porque "quero os todos pastos demarcados...Como é que posso com êste mundo?"; porque êsse livro funciona em qualquer página que o abrirmos, sendo composto de círculos concêntricos;

porque o ritmo é o comentário que o autor faz às suas palavras, sua personalidade; e porque nesse livro, o comentário é de um movimento amplo e de uma iniludível vivência;

porque Riobaldo viu, ouviu, cheirou, provou da terra e dos corações; porque se integrou êle nas apreensões de seus sentidos, dando uma medida de beleza e verdade às especulações;

porque as regiões compõem o mundo e o definem, como o tecido celular define o organismo;

porque o pouco que sabemos, êste livro ordena e nos ensina;

porque o Brasil existe; porque os brasileiros existem;

porque seguimos todos através do grande sertão, e aos poucos nos distinguimos no lusco-fusco do mato;

porque um livro como êsse é guardado para sempre;

eu o louvo com modéstia e espanto. (CAMPOS, 1956, p. 45) ${ }^{6}$

Em maio de 1956, publicou-se Grande sertão veredas, pela José Olympio Editora. Em outubro do mesmo ano, Paulo Mendes Campos, cronista da Revista Manchete, revela seu louvor modesto e espanto quando do aparecimento do romance rosiano. No espaço limitado da Revista, traz ao público seu texto, intitulado “Grande sertão: veredas (João Guimarães Rosa)". Como é característica do jornalismo impresso, o texto é bastante breve, próprio das colunas periódicas, mas apresenta, imbuído do seu compromisso com a crônica, uma interpretação complexa do livro de Rosa. Trata-se do arcaico e do moderno, de que falaremos mais adiante. Neste momento, gostaríamos de destacar alguns pontos das reflexões de Campos.

O primeiro deles é a particularidade quase de "convite" à leitura. Neste bojo, fizemos um balanço de quantas vezes o termo "porque" se repete ao longo do texto. Entendemos este uso como marca linguística que remete a uma tentativa ou, ainda, uma justificativa de dizer o valor de determinada coisa, neste caso, o recém-publicado Grande sertão: veredas. Em nossa análise, contamos exatamente vinte e seis vezes a marca do "porque", como dissemos, arrolado

\footnotetext{
${ }^{6}$ O material, no qual se insere "Grande Sertão: Veredas (João Guimarães Rosa)", de Paulo Mendes Campos, faz parte do acervo do Instituto Moreira Salles. Disponível em: https://cronicabrasileira.org.br/cronicas/7214/grandesertao-veredas-joao-guimaraes-rosa. Acesso em: 17 de junho de 2020. Em anexo, inserimo-lo no formato de publicação original. Trata-se de um recorte.
} 
em uma intenção de mostrar a grandiosidade da narração de um Riobaldo, homem anônimo, mas habitante de todos os lugares, como a leitura de Campos faz crer.

Em suma, reconhecendo-a como uma leitura de "primeiras horas", ou seja, de uma recepção presente muito próxima ao aparecimento da narrativa, é compreensível o intento do cronista no "desejo" de convencer o leitor, aquele da Revista Manchete, quem sabe, em adquirir e ler o romance, o qual, naquele momento, ainda era desconhecido do grande público. Todavia, vale a pena ressaltar que, embora Paulo Mendes Campos recorra a termos mais técnicos, como "hipérbatos, pleonasmos, anacolutos, anástrofes, prosopopeias, hipérboles, perífrases, metonímias, sinédoques", sua real intenção não é crítica, antes participa de um "espanto" de um cronista/leitor que, ao ler a obra, lança um olhar poético sobre ela, preferindo as imagens e as emoções de primeira hora aos argumentos conceituais de um crítico. Na esteira da recepção do romance Grande sertão: veredas entre os escritores, Clarice Lispector em uma carta a Fernando Sabino, datada de 11 de dezembro de 1956, de Washington, como o "espanto" de Paulo Mendes Campos, revela seu entusiasmo com a obra recém-publicada de Guimarães Rosa, segundo ela, livro que a deixou "até tola", como ela afirma na carta endereçada ao amigo cronista.

Fernando, estou lendo o livro de Guimarães Rosa, e não posso deixar de escrever a você. Nunca vi coisa assim! É a coisa mais linda dos últimos tempos. Não sei até onde vai o poder inventivo dele, ultrapassa o limite imaginável. Estou até tola. A linguagem dele, tão perfeita também de entonação, é diretamente entendida pela linguagem íntima da gente - e nesse sentido ele mais que inventou, ele descobriu, ou melhor, inventou a verdade. Que mais se pode querer? Fico até aflita de tanto gostar. Agora entendo o seu entusiasmo, Fernando. Já entendia por causa de Sagarana, mas este agora vai tão além que explica ainda mais o que ele queria com Sagarana. O livro está me dando uma reconciliação com tudo, me explicando coisas adivinhadas, enriquecendo tudo. Como tudo vale a pena! A menor tentativa vale a pena. Sei que estou muito confusa, mas vai assim mesmo, misturado. Acho a mesma coisa que você: genial. Que outro nome dar? Esse mesmo. Me escreva, diga coisas que você acha dele. Assim eu ainda leio melhor. Um abraço da amiga. (LISPECTOR, 2011, p. 169)

Neste ritmo quase emocional, que comentamos, enquadram-se também os inúmeros "porquês", nascidos como de uma vontade de participar da novidade do que representava aquele 


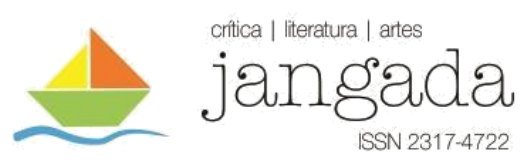

romance que acabava de se inserir na riqueza cultural do Brasil. Este, ao chegar, "ensina", feito distinção no "lusco-fusco do mato".

Dada a riqueza poética do excerto acima, é inegável seu valor como crônica de interpretação. Dessa forma, Campos cita trechos da narrativa rosiana para transbordar sua impressão de leitura em um tom emocional, finalizando com um "espanto". Assim, da sua reflexão, as imagens do leitor/cronista juntam-se às questões levantadas pela própria obra. Vejamos: "Porque a invenção dêsse livro é constante como os movimentos da natureza e as inquietações do pensamento, nessa reciprocidade que faz o homem patético perante as vagas do oceano, e fria e inapelável a órbita das êstrelas" (CAMPOS, 1956, p. 45).

"Vagas do oceano", "órbita das êstrelas": São maneiras, como vemos, de tentar dizer o que significa aquele Grande sertão de Riobaldo, em que confluem a grandiosidade da obra e o desejo de mostrar, poeticamente, o recém-conhecido. Ao final da crônica literária, a “impressão" desse leitor parece "desmanchar-se" quase em uma forma poética, imersa em "porquês":

porque o pouco que sabemos, êste livro ordena e nos ensina;

porque o Brasil existe; porque os brasileiros existem;

porque seguimos todos através do grande sertão, e aos poucos nos distinguimos no lusco-fusco do mato;

porque um livro como êsse é guardado para sempre. (CAMPOS, 1956, p. 45)

Em "Apresentação" ao livro De um Caderno Cinzento: Crônicas, aforismos e outras epifanias, de Paulo Mendes Campos, Elvia Bezerra levanta algumas questões fundamentais para a nossa análise da crônica sobre o Grande sertão: veredas deste conhecido cronista mineiro. No texto "No laboratório do cronista", ela sublinha que Campos:

Era um notável frasista, e estranhamente declarou sua antipatia por aforismos dizendo que os construía apenas como "jeito de fazer crônica de vez em quando". Com esse "jeito" temperou muito de suas páginas, e chegou mesmo a formar, apenas com máximas, toda uma coluna da série. (BEZERRA, 2015, p. 9)

Com esse esclarecimento de Bezerra, organizadora do livro de Campos, mencionado anteriormente, podemos apontar uma marca da escritura na crônica, corpus deste trabalho. $\mathrm{Na}$ última parte do texto, frases de efeitos, soltas, somam-se uma as outras, como dissemos, 
iniciadas em "porquês", para levantar máximas reflexivas advindas de uma leitura do romance. Queremos dizer, com isso, que, no uso de sua técnica de escrita, Campos ordena sua reflexão, na qual apresenta o tom de "convite à leitura", como já explicamos, e, ao mesmo tempo, de louvor somado ao "espanto".

Nesta particularidade "frasista", Campos expõe toda a sua capacidade sintética. Assim, temos a impressão que, ao ler o "espantoso" romance, em que, naquele momento, sendo impossível defini-lo, haja vista que a fortuna crítica do livro ainda não se formara, o cronista traça "elogios modestos" para aquela narrativa, estando, portanto, no plano da crônica, no início da recepção desta "estória" riobaldiana.

Explicado o caráter não intencional de fazer crítica, faz-se mister comentarmos a interpretação deste cronista, em tom de quase "conversa literária", como faz lembrar o nome da coluna da Manchete, naquilo que mais o impressionou, levando-o à vontade de louvar com "modéstia" o novo trabalho de seu conterrâneo mineiro. Para isto, será necessário recorrermos, em alguns momentos, aos intérpretes "mais especializados", porque vários pontos levantados por Paulo Mendes Campos são matéria de reflexão da crítica. Temos, aqui, a clave da questão. O que chamamos de "vários pontos" são como matérias ou assuntos que diversos estudiosos problematizam para melhor esclarecer as suas abordagens. Destarte, Campos, como cronista, “joga" com o emocional. No entanto, emocional, aqui, não significa ausência de consciência da presença de questões, que ele chama, poeticamente, de "tecido celular" que "define o organismo". Do outro lado, a crítica, interessada neste "organismo" que é a própria obra, explica-a em conceitos.

No mesmo contexto jornalístico, quando do aparecimento de Grande sertão: veredas, Antonio Candido, no Suplemento Literário, $\mathrm{n}^{\circ}$ 1, do Estado de S. Paulo, publica em 6 de outubro de 1956, sua interpretação do romance (vide anexo). Trata-se do primeiro texto crítico de Candido a respeito da novidade rosiana. Texto breve, dado que se encontra no espaço limitado do Jornal, o chamado "Suplemento", apresenta alguns pontos interessantes para situarmos o "tom" crítico deste importante intelectual brasileiro, servindo-nos para efeito de comparação com a outra recepção de Grande sertão: veredas, a crônica de Campos:

Este romance é uma das obras mais importantes da literatura brasileira — jacto de força e beleza numa novelística algo perplexa como é atualmente a nossa. Não segue modelos, não tem precedentes; nem mesmo, talvez, nos livros anteriores do autor, que, embora de alta qualidade, não apresentam a sua 
característica fundamental: transcendência do regional (cuja riqueza peculiar se mantém todavia intacta) graças à incorporação em valores universais de humanidade e tensão criadora. (CANDIDO, 1956, p. 2)

No excerto da crítica de Candido no Suplemento, temos configurado seu juízo em relação a este romance. No início, ele declara ser a obra uma das mais importantes da literatura brasileira. Objetivamente, como é característica do texto crítico, ao estabelecer o lugar deste livro, Candido sublinha a ausência de modelos anteriores, situando-o em comparação com outros trabalhos ficcionais do autor. Sagarana, por exemplo, já tinha sido publicado, em 1946. Portanto, o escritor mineiro não era desconhecido do cenário intelectual brasileiro. Poder-se-ia falar, aqui, de certo "horizonte de expectativa", para utilizarmos um termo dos estudos da Estética da Recepção alemã, com o fim de melhor compreender esse lugar de Grande sertão: veredas no conjunto da obra de Rosa, não concluída de todo, naquele momento da recepção, tanto de Candido, quanto de Campos. Segundo Jauss:

\begin{abstract}
A literatura como acontecimento cumpre-se primordialmente no horizonte de expectativa dos leitores, críticos e autores, seus contemporâneos e pósteros, ao experienciar a obra. Da objetivação ou não desse horizonte de expectativa dependerá, pois, a possibilidade de compreender a apresentar a história da literatura em sua historicidade própria. (JAUSS, 1994, p. 26)
\end{abstract}

Para a reconstituição da recepção da obra de Guimarães Rosa naquele momento, deve ser analisada não considerando as obras posteriores a Grande sertão: veredas, isto é, a partir do "olhar" de uma recepção de hoje, sabedores que somos que após o aparecimento do romance de 1956, ainda temos: Primeiras estórias (1962), Tutaméia (1967), e, postumamente, Estas estórias (1968) e Ave, Palavra (1970).

O crítico Antonio Candido define a importância do romance rosiano com base na falta de modelos e na própria produção anterior de Guimarães Rosa. Candido particulariza Grande sertão: veredas, naquilo que ele chama de "característica fundamental". Vejamos: “transcendência do regional [...] graças à incorporação em valores universais". Somado a este primeiro juízo crítico, ele acrescenta: "Há no livro uma estratificação de interesses, combinados e organizados a cada passo pelo autor na trama expositiva - do pitoresco regional à preocupação moral e metafísica" (CANDIDO, 1956, p. 2). Vê-se, neste fragmento, a ênfase do crítico na particularidade deste novo livro de Guimarães Rosa, no qual se coloca em 
movimentos que nascem "de dentro para fora" (CANDIDO, 1956, p. 2), em contraposição àquela outra ficção regionalista, anterior ao Grande sertão, que tinha como viés o trabalho "de fora para dentro" (CANDIDO, 1956, p. 2).

Da abordagem crítica de Candido, voltemos a considerar e problematizar mais de perto a recepção do cronista, no qual enfatizamos este caráter universal, posto na narração de Riobaldo. Na crônica, Campos ressalta a particularidade oral dessa narrativa, prefigurada no verbo "escutar", como demonstra o trecho seguinte: "porque devemos escutar uma história ao amanhecer, outra ao meio-dia, outra ao cair da noite; uma história na infância, outra ao abrir-se das luzes e das sombras da maturidade, outra quando um farol no golfo escuro decidir o caminho da velhice" (CAMPOS, 1956, p. 45).

No início de sua crônica, o autor já mostra aos leitores do jornal o que é fundamental considerar neste livro. Trata-se de um enredo que emerge das forças do contar e do escutar, de um ouvir, agora, necessário, "porque êsse livro conta uma história que ainda não ouvíramos, que precisávamos ouvir, uma história que agora se torna impossível imaginar não existindo" (CAMPOS, 1956, p. 45). No fundo, Campos aborda um enredo que apresenta um teor de "formação" naquele narrador-personagem, neste caso, de um Riobaldo criança, jovem e velho. Em suma, para isto, ele expõe esta questão por um longo período, no qual "transborda" o texto em igual beleza, lembremos que se trata de uma crônica. Esta também "flerta" com qualquer coisa de intenção ensaística. Falaremos disso mais adiante.

Da universalidade e metafisica apontadas por Candido, Campos, leitor/cronista, "responde" e devolve à engenhosidade do romance, com outras tantas belas imagens, nascidas da cabeça do poeta: "porque esse livro repete a parábola da vida humana sobre a terra e nos molha no frescor das primitivas vegetações terrestres até aclarar-nos ou ofuscar-nos em definitivas indagações da consciência” (CAMPOS, 1956, p. 45, grifo nosso). Neste trecho, o autor junta a parábola, metáfora universal, daquilo que se repete e comunga em todos os homens, ao regional de um sertão que tem como base o primitivo, prefigurado na vegetação, na terra, nas veredas e encontros. Além disso, no excerto do cronista, vemos configurada a intersecção fundante entre o mito, o arcaico e o pensamento, revestido de modernidade. Nesta relação, é a intuição que traduz a vivência para realizações transmitidas e estendidas para intenções intemporais pela consciência do pensamento. Em Création littéraire et connaissance, capítulo "L’héritage mythique de la littérature", Hermann Broch afirma: 
Nascido da estrutura fundamental do homem, o mito e o Logos representam para ele o eterno puro e simples. Além deles e com eles, toda realização humana, seja no campo da linguagem, da figuração ou da ação, é transmitida ao longo da cadeia de gerações, tornando-se compreensível e traduzível para qualquer nova geração, além de promover a unidade da raça humana, que se estende além dos tempos e da atemporalidade de suas realizações, assim o homem também recebe a garantia do conhecimento intuitivo da intemporalidade. (BROCH, 1966, p. 247-248) ${ }^{7}$

Assim, neste imbricar "concêntrico" entre o "mito" e o "logos", vê-se que o sertão se mostra como sem limites, antes ele se espalha e se alarga: "Êsses gerais são sem tamanho. Enfim, a cada um o que quer aprova, o senhor sabe: pão ou pães, é questão de opiniães... o sertão está em tôda parte" (ROSA, 1956, p. 9-10). Do primitivo, arrola-se um mundo/sertão, no qual confluem a violência, o selvagem de um viver em sempre perigo: "Viver é muito perigoso... Querer o bem com demais força, de incerto jeito, pode já estar sendo se querendo mal, por principiar. Êsses homens! todos puxavam o mundo para si, para o consertar consertado" (ROSA, 1956, p. 18). Neste ínterim, ao enfatizar esta relação entre "a parábola da vida humana" e o "frescor primitivo", daquele lugar que se avança para todo um mundo, o cronista, poeticamente, insere o lugar do antigo e do arcaico neste sertão de perigos, onde até mesmo os seres são misturados, selvagens, beirando ao informe, isto é, significando o que não se ajusta em nenhuma forma fixa, o que evidencia o primitivo, como mostra o trecho do romance: "Como era o Hermógenes? Como vou dizer ao senhor...? Bem, em bró de fantasia: ele grosso misturado - dum cavalo e duma jibóia... O um cachorro grande" (ROSA, 1956, p. 206).

Seguindo a crônica de Campos, revelam-se, em sua reflexão, estes "homens", que “puxavam o mundo para si”. Para ele, Riobaldo está em todos os lugares e homens, onde, ele, o cronista, se inclui:

Porque os homens são um único homem, e um único homem são todos os homens, porque Riobaldo estêve na Grécia, no castelo que preparava a guerra

\footnotetext{
${ }^{7}$ No original (BROCH, 1966, p. 247-248), lê-se: Nés de la structure fondamentale de l'homme, le mythe et le Logos représentent pour lui l'intemporel pur et simple. Outre qu'en eux et avec eux toute réalisation humaine, qu'elle ait eu lieu dans le domaine de la langue, de la figuration ou de l'action, est transmise le long de la châine des générations et qu'elle est rendue compréhensible et traduisible à toute génération nouvelle, outre que par là s'attestent l'unité du genre humain qui s'étend par-delà les époques et l'intemporalité de ses réalisations, l'homme reçoit aussi par là la garantie de la connaissance intuitive de l'intemporalité."
} 
santa, na grande revolução libertária, no sertão de Minas entre os jagunços, e Riobaldo está a meu lado; porque a metafísica de Riobaldo percorre os tempos do mundo de ponta a ponta; porque Riobaldo é ação que se contempla e o pensamento que sai armado cavaleiro. (CAMPOS, 1956, p. 45, grifo nosso)

Temos, aqui, a subjetividade do autor se colocando na recepção deste romance, publicado poucos meses antes da crônica de Campos. Estar ao "meu lado", significa participar, afetivamente, de um universo, como afirma Candido de "substância universal" (CANDIDO, 1956, p. 2). Como se vê no excerto, em imagens de um Riobaldo viator do mundo, ele só pode armar-se "cavaleiro" do pensamento e da contemplação, neste caso, do próprio Eu, que acaba sendo, ao mesmo tempo, Todos. Nestas "camadas" reflexivas, de conflitos internos, corrobora aquilo que Candido diz ser da ordem do "dentro para fora".

Em 1958, Cavalcanti Proença, em Trilhas do Grande Sertão, utiliza-se dessa perspectiva de um Riobaldo cavaleiro para desenvolver a sua crítica. No capítulo "Don Riobaldo do Urucúia, cavaleiro dos campos gerais", após uma pequena epígrafe da Demanda do santo Graal, ele sublinha:

Que não houve, apenas, paráfrase de uma lenda, é evidente. Mas o tipo cavalheiresco de Riobaldo despertou, associativamente, no acervo de impressões de leitura do autor, ressonâncias que acabaram por sintonizar até os componentes do romance, onde se pode rastrear uma propensão arcaizante de efabulação, com reflexos no próprio vocabulário. (PROENÇA, 1958, p. 15)

Não se trata de crítica de veiculação jornalística, tampouco de uma recepção que chamamos de "primeiras horas", já que o trabalho de Proença é datado de 1958. Entretanto, vemos como questões abordadas pelo cronista, mais tarde, são evidenciadas pela crítica. Assim, da imagem poética de Campos que se refere a um ex-jagunço que sai armado cavaleiro pelo pensamento, pode-se verificar todo um manancial crítico. Por exemplo, como se vê na crítica de Proença ao tratar, entre outras temáticas, de um Riobaldo que carrega em si a força de um "Don", como faz lembrar o capítulo da crítica, citado anteriormente. Não sabemos, para este efeito, se Proença leu a crônica de Campos, entretanto, é inegável a possibilidade da relação.

Seguindo a interpretação de Campos sobre Grande sertão, temos o caráter filosofante do agora fazendeiro velho, de um ex-jagunço, que vive de "range rêde" (ROSA, 1956, p.11). 
Nesta reflexão do Jagunço letrado, configura-se o desconcerto e o perdido, para, talvez, acharse: "fillosofar é a solidão do homem anônimo e, no entanto, através da solidão este anônimo comunga na filosofia universal; porque só o exercício do sofrimento pode abrir esperanças ao pensamento de Riobaldo; e o pensamento de Riobaldo vai, perdido e achado" (CAMPOS, 1956, p. 45). No fragmento, uma questão se mostra fundamental para compreendermos a modernidade do que significa o pensamento deste fazendeiro de "range rêde". Trata-se de uma "filosofia universal" que, ao mesmo tempo, perfaz-se na modernidade, na medida em que traz para o primeiro plano a perspectiva do jagunço perdido, em que nasce do "exercício do sofrimento". Assim, ao comentar esse paralelo entre o universal e o pensamento "perdido", Campos nos revela os fundamentos dessa narração riobaldiana, no fundo, da modernidade do romance. Para esta abordagem, vale a pena recorrermos ao argumento de Anatol Rosenfeld a respeito da modernidade romanesca. Segundo ele, nestes romances, projeta-se:

O mundo a partir de uma consciência individual. O mundo é relativizado, visto em relação a esta consciência. [...] eliminando ou deformando o ser humano, a perspectiva "ilusionista" e a realidade dos fenômenos projetados por ela é expressão de um sentimento de vida ou de uma atitude espiritual que renegam ou pelo menos põem em dúvida a visão do mundo que se desenvolveu a partir do Renascimento. (ROSENFELD, 2009, p. 77-79)

Como podemos inferir a partir da interpretação da crônica, Riobaldo sendo moderno, por vezes, perde-se. Por outro lado, este pensamento perdido fê-lo comungar e participar de seu tempo, isto é, da modernidade que passa a invadir o romance, desestabilizando o sujeito, afastando-o cada vez mais das certezas absolutas. Neste bojo, é o sofrimento evidenciado no seu passado que o faz, em narração, organizar a matéria dificultosa: "Vivi puxando difícil de difícel, peixe vivo no moquém, que mói no asp'ro, não fantasêia” (ROSA, 1956, p. 11). Na crítica bem mais recente, Davi Arrigucci Jr. em $O$ mundo misturado: romance e experiência em Guimarães Rosa, afirma que se trata de uma narração que ronda "o múltiplo e labiríntico" (ARRIGUCCI JR., 1994, p. 7). Ora, o labiríntico, de que fala Arrigucci Jr., realiza-se neste "difícil de difícel" que representa a vida de outrora, agora, passada a limpo pelo fazendeiro Riobaldo. Ressaltado o caráter perdido do pensamento do narrador, Campos segue sua crônica, em sintética abordagem, evidenciando outra particularidade deste livro, que segundo ele, valese de um "espírito sem forma": 
Porque essa obra de arte, generosa como a fertilidade do solo, indo não sei onde, onde quer que o espírito a leve, tem a armação matemática com que se desenhou a harmonia do templo em louvor de um espírito sem forma, além de todos os cálculos; porque sempre, acima da sintaxe estruturada, há-de soprar o vento do espírito - a fim de que as contradições do nosso destino se realizem. (CAMPOS, 1956, p. 45, grifo nosso)

"Espírito sem forma", fundamentado na "armação matemática" do romance, condiciona a discussão que vê em Grande sertão: veredas qualquer coisa de selvagem, porque, em todo a sua "estrutura" é o não classificatório que se coloca. De acordo com Willi Bolle, "o texto de Grande sertão: veredas responde ao olhar de quem o lê e analisa; responde com um olhar indomado, suçuaranamente selvagem e cristalino, olhar de jaguar verdadeiro, olhar liso" (BOLLE, 1998, p.269). Desse modo, o “difícil de difícel” parece não se referir apenas à matéria do romance, ou seja, a vivência do narrador, alargando-se para a "armação", no qual, poeticamente, Campos lê como "harmonia do templo em louvor de um espírito sem forma" (CAMPOS, 1956, p. 45).

Na esteira da relação entre marcas universais e o moderno pensamento "perdido" do exjagunço, Campos revela a grande força deste livro rosiano: a vivência. Nestas experiências riobaldianas, o vivido, muitas vezes, encaminha-se na própria sensibilidade e sensações desse agora fazendeiro. Assim, no interior de sua vida emocional, ele explora os sentidos humanos para devolver, em narração, o poético, "a medida de beleza", no fundo, a sua verdade, daquilo que se "traduz" internamente, tantas vezes marcadas, no plano da narração, por interrupções, visto como assunto delicado, difícil de contar:

Como vou contar, e o senhor sentir em meu estado? O senhor sobrenasceu lá? O senhor mordeu aquilo? O senhor conheceu Diadorim, meu senhor?!... Ah, o senhor pensa que morte é chôro e sofisma - terra funda e ossos quietos... O senhor havia de conhecer alguém aurorear de todo amor e morrer como só para um. $\mathrm{O}$ senhor devia de ver homens à mão-tente se matando a crer, com babas raivas! ou a arte de um: tá-tá, tiro - e o outro vir na fumaça, de à-faca, de repêlo: quando o que já defunto era quem mais matava... O senhor... Me dê um silêncio. Eu vou contar. (ROSA, 1956, p. 579)

Sobre esta vivência de Riobaldo, em que nasce o contar, Campos interpreta: 
Sua personalidade; e porque nesse livro, o comentário é de um movimento amplo e de uma iniludível vivência; porque Riobaldo viu, ouviu, cheirou, provou da terra e dos corações; porque se integrou êle nas apreensões de seus sentidos, dando uma medida de beleza e verdade às especulações. (CAMPOS, 1956, p. 45)

Portanto, arrolado a sua característica de abordar um grande assunto de forma sintética, que, no gênero crônica, parece funcionar com maestria, Campos congrega, neste texto, toda a vivência de Riobaldo, que em "ritmo" traduz o comentário do "iniludível”, perfazendo-se em movimento do contado. Neste "contar", são as marcas vividas do narrador que aparecem em primeiro plano. Assim, sabemos, pela leitura e interpretação de conhecidos intérpretes, que a experiência/ vivência de Riobaldo perpassa pelo sofrimento, sobretudo daquele advindo de sua neblina, misto de Reinaldo/Diadorim, no fundo, a sua perturbação, inquietude e sua dúvida. Ainda nesta marca de autor "frasista", colocadas em estratégicas posições, o cronista finaliza a sua interpretação poética do Grande sertão: veredas, colocando-o no seu verdadeiro valor e lugar na literatura brasileira: na prosa-poética que interpreta o Brasil, que diz o que somos e como nos distinguimos em imenso "lusco-fusco do mato". Para além disso, ao dizer sobre nós, ele nos "ordena e nos ensina".

Em síntese, o cronista expõe como interpretação artística a sua leitura, "em modéstia", tendo consciência de que aquele romance carrega a grandiosidade, como "tecido célula" que "define o organismo" que é a própria obra, sua "matemática" em "espírito sem forma”, mas também é todo o Brasil. Nele, os "brasileiros existem”, estão poeticamente ao lado de Riobaldo, porque sendo o ex-jagunço habitante de todo o mundo, "seguimos todos através do grande sertão". Pode-se depreender da crônica, o que mais tarde a crítica especializada vai desenvolver num plano conceitual, onde o conhecimento e o método sociológico, muitas vezes, serão utilizados como maneira de interpretar este romance, que ao ser lançado, não se sabia o que era, não sendo possível defini-lo.

Trata-se de Grande sertão como obra que traduz, poeticamente, a terra, o homem e os problemas brasileiros. Em grande medida, é o que fará Antonio Candido com maior fôlego a partir do estudo O Sertão e o Mundo, publicado em 1957. Nele, o crítico desenvolve o caráter da experiência documentária de Rosa, ao lado da sua inventividade e capacidade de observador daquele mundo sertanejo, no qual ele expressa em moldes universais: 
Registrando o aparecimento de Grande sertão: veredas numa resenha breve, sugeri, sem especificar, êsse caráter de invenção baseada num ponto de partida reconstituído, que parece essencial ao livro. [...] A experiência documentária de Guimarães Rosa, a observação da vida sertaneja, a paixão pela coisa e o nome da coisa, a capacidade de entrar na psicologia do rústico — tudo se transformou em significado universal graças à invenção, que subtrai o livro da maneira regional, para fazê-lo exprimir os grandes lugares comuns, sem os quais a arte não sobrevive: dôr, júbilo, ódio, amor, morte, para cuja órbita nos arrasta a cada instante, mostrando que o pitoresco é acessório e na verdade, o Sertão é o Mundo. (CANDIDO, 1957, p. 5-6)

Comparando com seu trabalho anterior, a resenha do Suplemento Literário do Estado de S. Paulo, em 1956, nas "primeiras horas" do aparecimento de Grande sertão: veredas, Candido demarca seu "projeto crítico" na interpretação desse romance rosiano. Para ele, o crítico ressalta a particularidade do autor, em sua "invenção" ao documentar este sertão, inserindo-o, no entanto, em significação “universal”. Para isto, como é próprio do trabalho crítico, movimenta-se toda uma argumentação para melhor justificar e situar esta obra como "inventividade" da literatura brasileira, em suas próprias palavras, como "extraordinária obraprima" (CANDIDO, 1957, p. 5). Voltando-nos à crônica de Paulo Mendes Campos, vemos como nesta interpretação do cronista já ressoam ecos de questões, mais tarde desenvolvidas por diversos estudiosos da ficção rosiana, como se dá, por exemplo, com a problematização do livro como "tradutor inventivo" do Sertão, do Brasil e do Mundo.

Não estamos, com isto, com o intento de classificar a reflexão de Campos como crítica, como já tivemos oportunidade de explicar, antes preferimos entendê-la como interpretação inventiva, que soube, sinteticamente, abordar em imagens poéticas o essencial daquele livro. Na crônica, atenta-se à característica do antigo, da "primitiva vegetação", onde o mundo se encontra num único homem, mas, ao mesmo tempo, mostra o moderno pensamento do narrador-personagem. Nesta confusão, de um suposto pensar "perdido", acha-se o Brasil, visto na possibilidade do "sofrimento" que pode "abrir esperanças ao pensamento de Riobaldo", que, no fundo, também é de cada brasileiro. Assim, naquele ano de 1956, quando muitos não sabiam dizer o que representava Grande sertão: veredas, por não saber classificá-lo, tanto na matéria quanto na forma, o "olhar" poético de Campos soube interpretar, devolvendo com poesia, aquela "inventividade", de que Candido falará mais tarde. Na esteira dessa recepção crítica no contexto jornalístico, em 10 de novembro de 1956, no Jornal Correio da Manhã, em uma 
pequena resenha intitulada "Grande Sertão: veredas" (vide anexo), Octávio Mello Alvarenga afirma:

\begin{abstract}
Afinal, que vem a ser "Grande Sertão: veredas"? Romance, ou poema? Vasta sinfonia para a qual não se acha classificação? Mas definir o próprio romance já não é difícil? É meio de comunicação híbrido, desde a vertente. Seu valor? Aprisionar quem o lê; tornar-nos tão preocupados com Riobaldo quanto já o fomos pelo destino dos Três Mosqueteiros; fazer-nos participantes das alegrias e sofrimentos dos jagunços de Zé Bebelo, que vagam pelo Nordeste de Minas. É extasiar-nos diante de Diadorim, do Menino, do jagunço Reinaldo. Não há meio têrmo: é ficar mesmo extasiado. (ALVARENGA, 1956, p. 9)
\end{abstract}

Neste trecho da resenha, Alvarenga coloca-nos a problematização do romance naquele momento da recepção, no que diz respeito ao seu lugar, à sua classificação. De um ponto, no entanto, ele tinha razão, trata-se de um texto, que ele chama de "híbrido". Hoje, falamos com maior segurança de prosa-poética. Ao final do excerto citado, depois de inserir Grande sertão nos grandes "destinos", como dos "Três Mosqueteiros", portanto, de certa universalidade, ele assume o fundamento do livro, qual seja: de "participantes" do sofrimento daqueles personagens, afinal o itinerário de tantos jagunços, sobretudo de Riobaldo, serve para nos "extasiar". Neste sentimento de leitor que entra no "jogo" da obra, que se encanta com o lido, parece envolver-se o cronista Campos, que para não dizer "extasiar", prefere o tom mais dramático de um "espanto".

Desse modo, em "comunicação híbrida", podendo ser, como considera Alvarenga, "Romance ou poema", não estaria o cronista/poeta mais preparado para recepcionar aquela obra selvagem, que se nega à classificação, pois, carrega justamente em si a melhor entrega à novidade? São perguntas difíceis de responder, todavia, sabemos, pela leitura da crônica de Campos, como esse cronista soube com maestria penetrar no "íntimo" de Riobaldo, do seu pensamento que corrobora os "círculos concêntricos", como ele revela numa feliz expressão para aquele livro. Embora não seja preocupação sua classificar objetivamente a difícil narração riobaldiana, em imagens, ela movimenta todo o significado da recém-publicada narrativa.

Em relação a um possível "horizonte de expectativas", considerando as obras já publicadas de Rosa, haja vista que até 1956, Sagarana já estava em sua quarta reedição, e Corpo de baile, em janeiro do mesmo ano, teve sua primeira edição, não sabemos como tais narrativas Jangada | nr. 16, jun/dez, 2020 | ISSN 2317-4722 
auxiliaram o cronista na leitura de Grande sertão, ou ainda, serviram como base para pensar a novidade do romance segundo a produção ficcional anterior do autor de Sagarana, como demonstra Antonio Candido em sua Resenha de 1956. No que tange à expectativa e comparação de Grande sertão com as obras anteriores do autor, Sério Milliet em seu Diário Crítico (19551956), afirma:

Março, 19 - A princípio se ensaiando com "Sagarana". Admiráveis exercícios de estilo, a que se seguem os não menos brilhantes de "Corpo de Baile”. Brilhantes? Há algo de pejorativo no vocábulo: risquemo-lo. E digamos que, com "Corpo de Baile", alcança o autor a autenticidade que todos buscávamos. Mas com "Grande Sertão: veredas" temos o grito de independência de nossa literatura. (MILLIET, 1959, p. 196)

Para melhor refletirmos a recepção do Grande sertão, tendo como base o conhecimento ou não dessas obras anteriores, é interessante também o que diz Octávio Mello Alvarenga na Resenha do Correio da Manhã, no periódico de 10 de novembro de 1956.

Dizem que é moda falar de Guimarães Rosa. Pois fiquemos na moda: vamos falar do livro que acabamos de ler: "Grande Sertão: veredas".

Do autor não conhecíamos nenhum dos trabalhos anteriores. Será honesto, então, nos referir ao último, quando fomos alertados que "Sagarana" e "Corpo de Baile" constituem leitura preparatória para "Grande Sertão"? O inconveniente não existe, de todo. A fôrça com que êste livro, por si só, exige u'a manifestação é a melhor resposta a quem formule pergunta idêntica à nossa. (ALVARENGA, 1956, p. 9)

Na esteira da reflexão de Alvarenga, não sabemos da real recepção do romance pelo leitor/ cronista, isto é, se o autor passou pela leitura das obras anteriores, como foi alertado a Alvarenga, da possível necessidade da "leitura preparatória". No entanto, como é acertadamente demonstrado pelo resenhista, é mister uma "resposta" diante da "força" inventiva que representa aquela novidade de Rosa. Obviamente, trata-se de uma "resposta" criativa, mas para aquele momento de ainda incerteza em relação ao Grande sertão, mostrou-se, em nosso entendimento, valiosa, pois, em imagens, deu conta de vários aspectos da obra, sobretudo na 
ênfase da interseção entre a universalidade antiga, dado em "frescor das primitivas vegetações terrestres" ao lado do moderno pensamento "perdido e achado" de Riobaldo.

A interpretação do "primitivo" parece, conforme a resenha de críticos, assim como da crônica de Campos, ter uma importância na leitura desse romance. De acordo com Alvarenga: "Grande Sertão: veredas é a mais corajosa expressão, que conhecemos, das fontes da sensibilidade do Brasil-Sertão. A nova língua de Guimarães Rosa nos conta história de validade universal, com elementos de maior primitivismo e inocência" (ALVARENGA, 1956, p. 9, grifo nosso). A resenha é posterior à crônica de Campos, mas vemos como esta particularidade do "primitivo", lembrada por este último, coloca-se na clave das leituras das resenhas daquele ano, presente, inclusive, nas críticas mais atuais. Para isto, é uma "resposta" que nasce da própria coerência da obra, do "seu tecido celular", imbuída em passagens como esta: "Lugar sertão se divulga: é onde os pastos carecem de fechos onde um pode torar dez, quinze léguas, sem topar com casa de morador; é onde criminoso vive seu cristo-jesus, arredado do arrôcho de autoridades" (ROSA, 1956, p. 9).

Por fim, exposta todas estas questões no que tange à importância do texto de Campos, como leitura/interpretação inventiva do romance rosiano, perguntamo-nos: qual a diferença desta crônica daquelas mais presas ao cotidiano, ou ainda, qual a justificativa para tamanhas observações acertadas de Grande sertão: veredas, desenvolvidas por meio de frases sintéticas, quase beirando as máximas, ao lado de uma complexa reflexão que se configura em imagens que se "amontoam" para emergir uma espécie de leitura poética?

Em todo o trabalho, falamos em interpretação artística, na qual se mostra, por vezes, poética. Por outro lado, como dissemos anteriormente, é flagrante a peculiaridade da crônica, vista, principalmente, em seu intencional objetivo de desenvolver um "comentário" sobre outra obra. Acreditamos, neste sentido, tratar-se de uma forma híbrida, misto de crônica e ensaio. Poder-se-ia, portanto, conceituá-la como crônica-ensaística. Para isto, faz-se necessário problematizarmos, ainda que brevemente, essa relação, na qual tentaremos entendê-la como texto de “fronteira". Sylvio Lago Jr. em $O$ ofício do ensaísta, sublinha:

Com relação à crônica, ela pode, às vezes, avizinhar-se ao ensaio quando se reveste de caracterização estritamente literárias. Observemos, todavia, que a crônica possui algumas acepções que são distintas do ensaio, principalmente quando têm feição jornalística, retratando ou não o cotidiano efêmero ou com textos de qualidades literárias perduráveis. [...] Wilson Martins diz que "a 
crônica é a literatura do jornalismo". Na maioria das vezes, as crônicas podem ser reunidas em ensaios, dando nascimento a um livro. Isso justifica o aparente paradoxo do jornal passando a constituir-se em grande fenômeno da cultura democrática. (LAGO JR., 2000, p. 8)

Do comentário de Lago Jr., é possível depreendermos a difícil tarefa que é classificar, muitas vezes, os gêneros. De outra forma, como o "desclassificado" Grande sertão, preferimos colocá-la nesta zona fronteiriça, em que as características de um e de outro gênero encontramse, estando, em harmônica convivência. Uma outra questão que "salta aos olhos" diz respeito à extensão. Ainda segundo Lago Jr., "em linhas gerais, pode-se considerar que a brevidade é um procedimento ancestral na construção dos ensaios" (LAGO JR., 2000, p. 8). Para a crônica, não são necessários grandes comentários, porque sabemos que a brevidade faz parte do mundo desse gênero. Destarte, há outro aspecto demasiadamente importante para situarmos. Trata-se do ensaísta como aquele que "informa" e "forma" os leitores, como revela Lago Jr.: "como o intérprete na música, o ensaísta assume, assim, o papel de mediador entre a obra e o autor, entre a obra e o leitor, realizando a tarefa de informar e formar o público que lê, revelando-lhe novos aspectos, descobertas e visões complementares" (LAGO JR., 2000, p. 8).

Conforme os argumentos de Lago Jr. sobre o ensaio, indagamo-nos: não estaria implicada nesta particularidade a real intenção de Paulo Mendes Campos ao interpretar Grande sertão, devolvendo aos leitores da Revista Manchete certa "formação", ressaltando "visões complementares" para aqueles que irão ler o romance de Rosa? Todavia, sabemos, como gênero que flerta com o ensaio, que Campos não tinha intenção nenhuma em esgotar o assunto, tampouco interpreta Grande sertão por meio de métodos comparativos, como é comum na crítica, nem "abre mão" de sua emocional subjetiva cronista. No fundo, o que ele pretende é que o leitor da Revista também participe do grande "espanto" que é a experiência do contato com a narração de um ex-jagunço, para, quem sabe, depois de lida a história de Riobaldo, mantenha também essa "estória" guardada para sempre.

\section{CONSIDERAÇÕES FINAIS}

No imenso cabedal dos estudos da obra de Guimarães Rosa, sobretudo daqueles que envolvem a recepção crítica ou não, é inegável certo "silêncio" a respeito da crônica "Grande Sertão: veredas (João Guimarães Rosa)", do cronista Paulo Mendes Campos, veiculada no contexto 
jornalístico. Assim, neste artigo, nosso intento foi resgatá-la, pois este texto representa uma reflexão/interpretação valiosa do romance rosiano, principalmente se considerarmos que se trata de recepção de "primeiras horas".

$\mathrm{Na}$ crônica, fica evidente a pretensão de uma leitura do romance, que se envereda por um viés artístico, assim como deixa clara uma reflexão que se dá na forma de "espanto" diante daquela obra recém-publicada. Dessa maneira, elegemos esta leitura/comentário da narrativa de Guimarães Rosa como base de nossa abordagem, e, para isso, dialogamos com outros intérpretes da obra do escritor mineiro, com o fim de melhor situar a particularidade da leitura de Paulo Mendes Campos, realizada artisticamente, sendo, portanto, tarefa que foge do mero trabalho crítico, para pensar a narração de Riobaldo como discurso que interpreta um Brasil. No texto, o autor soube articular uma reflexão que eleva uma vivência espontânea e emocional de um ex-jagunço, para inseri-lo definitivamente na literatura brasileira, sendo, pois, “impossível imaginar não existindo". Neste sentido, a crônica de Campos deve ser compreendida como recepção singular, pois está situada no momento recente do aparecimento de Grande sertão: veredas, assim como nasce da cabeça de um cronista, que, ao ler a narrativa rosiana, elege uma maneira particular de interpretar a obra, diferenciando-se, então, da recepção mais crítica, divulgadas em vários suplementos de jornais da época. Em suma, "Grande Sertão: veredas (João Guimarães Rosa)", do cronista mineiro, deve ser lido como texto situado num tempo histórico, ou seja, na recepção de "primeiras horas" da narrativa rosiana, segundo a qual guarda seu caráter de "espanto", mas também como crônica/leitura que mostra a sua beleza particular.

\section{REFERÊNCIAS BIBLIOGRÁFICAS}

ARRIGUCCI JUNIOR, Davi. O mundo misturado: romance e experiência em Guimarães Rosa. In: Novos Estudos CEBRAP, São Paulo, n. 40, p. 7-29, nov. 1994.

ALVARENGA, Octávio Mello. Grande Sertão: veredas. In: Correio da Manhã, Rio de Janeiro, n.19.519, p. 9, 10 nov. 1956.

BEZERRA, Elvia. O Laboratório do Cronista. In: CAMPOS, Paulo Mendes. De um Caderno Cinzento: crônicas, aforismos e outras epifanias. Org. Elvia Bezerra. São Paulo: Companhia das Letras, 2015, p. 7-18.

BOLLE, Willi. O sertão como forma de pensamento. In: SCRIPTA, Belo Horizonte, v.2, n.3, p. 259-271, $2^{\circ}$ sem., 1998. 
BROCH, Hermann. L'héritage mythique de la littérature. In: BROCH, Hermann. Création littéraire et connaissance. Trad. Albert Kohn. Paris: Gallimard, 1966. p. 247-256.

CANDIDO, Antonio. Grande Sertão: veredas. In: O Estado de S. Paulo, Suplemento Literário, n.1, p. 2, 6 out.1956.

O sertão e o mundo. In: Diálogo. Revista de Cultura (número especial sobre Guimarães Rosa), São Paulo, n. 8, p. 5-18, nov., 1957.

CAMPOS, Paulo Mendes. Grande sertão: veredas (João Guimarães Rosa). In: Manchete, Rio de Janeiro, n. 234, p. 45, 13 out. 1956.

JAUSS, Hans Robert. A História da Literatura como Provocação à Teoria Literária. Trad. Sérgio Tellaroli. São Paulo: Ática, 1994.

LAGO JR., Sylvio. O ofício do ensaísta. In: Revista Logos: comunicação e universidade, Rio de Janeiro, n. 13, p. 5-9, 2 sem., 2000.

MILLIET, Sérgio. Diário Crítico (1955-1956). São Paulo: Martins, 1959. v. 2.

PROENÇA, Manuel Cavalcanti. Trilhas do Grande Sertão. Rio de Janeiro: Departamento de Imprensa Nacional, 1958.

SABINO, Fernando; LISPECTOR, Clarice. Cartas Perto do Coração. Rio de Janeiro: Record, 2011.

ROSA, João Guimarães. Grande sertão: veredas. Rio de Janeiro: José Olympio, 1956. Ave, Palavra. Rio de Janeiro: José Olympio, 1970.

ROSENFELD, Anatol. Reflexão sobre o romance moderno. In: Texto e Contexto I. 5. ed. São Paulo: Perspectiva, 2009, p. 75-97. 


\section{ANEXOS}

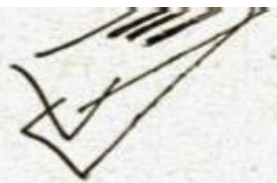

Porque casse livro conta uma his. tória que ainda nāo ouvircmos, que precisávamos ouvir, uma história que agora se torna impossivel imaginar nāo existindo; porque devemos es. cutar uma história as amanhocer. outra ao meio-dia, outra as cair da noite; urna história na infincia, ou tra ao abrir-se das luzes e das sombras da maturidade, outre quando um farol no golfo escuro decidir o caminho da velhice; porque há uma história no princípio, outra no meio, outra no fim do mundo: porque as très hístórias sấo uma única histó. ria : os enredos do homem com sua fôrça e seu mêdo, e a muher com sua fragilidade e sua coragrn: porque èsse livro repete a paribola da vida humana sóbre a terra e nos mo. tha no frescor das primitivas vegeta. çōes terrestres ató aclarar-nos ou ofuscar-nos $\mathrm{cm}$ definitivas indagaçöes da consciência; porque os homens são um único homem, $e$ um ínico homem săo todos os homens: porque Riobaldo estève na Grécia, no cas. telo que preparava a guerra santa, na grande revoluçäo libertária, no ser. tão de Minas entre os jaganços, e Riobaldo está a meu lado; porque a metafisica de Riobaldo percorre os tempos do mundo de ponta a ponta: porque Riobaldo é a ação qù se con. templa e o pensamento que sai arma. do cavaleiro:

porque a invenção dèsse livro $\hat{~}$ constante como os movimentos da natureza e as inquietaçōes ds pensamento, nessa reciprocidade que faz - homen patético perante is vagas do oceano, e fria e inapelável a ór bita das estrélas:

porque filosofar ć a solidão do homem anônimo c, no entanto, através da solidẩo êste anônimo comanga na filosofia universal; porque só o exer. cício do sofrimento pode abrir esperangas ao pensamento de Riobaldo; co pensamento de Riobaldo vai, perdido c achado, como um bando de homens armados através do sertão: porque essa obra de arte, generosa como a fertilidade do sob, indo nẫo sei onde, onde quer que o es. pirito a leve, tem a armaçio natemá. tica com que se desenhou a harmonia do templo em louvor de um es.
“Grande Sertão: Veredas"

\section{(João Guimarães Rosa)}

pírito sem forma, além de todos os cálculos; porque sempre, acima da sintaxe estruturada, há-de soprar vento do espirito - a fim de que a contradiçōes do nosso destino se rea liecm:

porque tôdas as partes dêsse livro cooperam entre si o aspiram a um fim; porque tódas as suas tiguras cooperam entre si e aspiram a um fim: porque seus hipérbatos, pleonas. mos, anacolutos, anástrofes, idiotis. mos, prosopopéias, hipérboles, peri. frases, metonimias, sinédoques, cooperam entre si e aspiram a um fim: c o fim a que aspiram é o entendi. mento e a denúncia dos homens; para que éstes nâo continuem matéria de escaindalo mas ponto de partida à vi da comum, o amor comum;

e ainda porque nesse livro se repetem a perplexidade das lendas mai antigas, o bem e o mal dos mais ve thos humanismos; "cu careço de que - bom seja bom o o ruim ruim que dum lado esteja o prêto e do outro o branco, que o feio fique bem apar. tado do bonito e a alegria longe da tristeza"; porque "quero os todos pastos demarcados... Como é que posso com éste mundo ?"; porque ćsse livro funciona em qualquer página que o abrirmos, sendo compos. to de círculos concêntricos:

porque o ritmo é o comentário que o autor faz às suas palavras, sua per. sonalidade; e porque nesse livro, o comentário é de um movimento am. plo e de uma iniludivel vivência;

porque Riobaldo viu, ouviu, chei. rou, provou da terra e dos corações: porque so integrou êle nas apreen. sôes de seus sentidos, dando uma me. dida de helera e verdiade àm mpecule. şốes;

porque as regiốes compōem o mun. do $e$ o definem, como o tecido celular define o organismo;

porque o pouco-que sabemos, is. se livro ordena e nos ensina:

porque o Brasil existe; porque os brasileiros existem;

porque seguimos fodos atrayés dô grande sertĩo, e aos poucos nos distinguimos no lusco-fusco do mato; porque um livro comp êsy é guar dado para sempre;

eu o louvo com modéstia e espanto.

CAMPOS, Paulo Mendes. Grande Sertão: veredas (João Guimarães Rosa). Manchete, Rio de Janeiro, n. 234, p. 45, 13 out.1956. 


\section{LITERATURA}

Joăo Guimarães Rosa, GRANDE SERTAO: VEREDAS, Livraria JOSÉ Olympio Editora, Rio de Janeiro. 1956, 594 pags.

Este romance é uma das obras mais importantes da jiteratura brasileira - jacto de força e beleza numa novelistica algo perplexa como é atualmente a nossa. Náo segue modelos, năo tem precedentes: nem mesmo, talvez, nos livros anteriores do autor, que, embora de alta qualỉdade, nẩo apresentam a sua caracteristica fundamentâl: transcendencia do regional (euja riqueza peculiar se mantém todavia intacta) graças á incorporaçăo em valores universais de humanidade e tensấo criadora.

E' uma historia de jagunços do Norte de Minas na forma do monoloso ininterrupto, sem divisẳo ou capitulo, de um velho fazendeiro narrando como se tornou membro e narinal ram em torno da vinganca contra companheiros felóes que mataram á traiça o grande chefe de todos; mas miolo nutritivo é - não sei se misa a expressáo ou a personall. dade do narrador, a cuja amadurecimento presenciamos no correr do livro, $S$ áo, $\mathrm{em}$ todo caso, a estupenda visăo do mundo $e$ a inquietude interior elaboradas ao longo do seu interior eloquencia e poesia.

Há no livro uma estratificação de interésses, combinados e organizados a cada passo pelo autor na trama expositiva do pitoresco resional á preocupaçăo moral e metarisica.

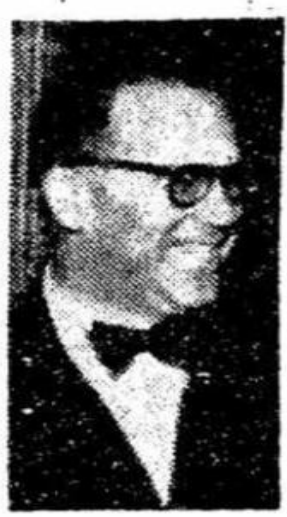
da ficç̄o re gionalistica, feita quase sempre "de fora revelando escritor simpatico. c o mpreensivo. mas separado da realidade es sencial do mundo que descreve; e que enxerta num contexto erucito elementos mais ou menos bem apreendidos da $p$ ersonalidade. costumes, linguagem do homem rustico. sens, năo integracăo nec a pleno efeito da obra de arte. Fn Grande Sertaso: Veredas, ap:oveitamento literario do mate. rial observado na vida sertaneja se dá "de dentro para fora", no espirito, mais que na forma. O autor inventa, como se, havendo descoberto as leis mentais e sociais do mun du que descreve, fundisse num grande bloco um idioma e situaçōes artiticiais. embora regidos por acontecimentos e princípios expressionais potencialmente contidos no que registrou e sentiu. Sob este aspecto ao mesmo tempo de anotaçăo e cons truçaso, lembra os compositores que infundiram o espirito dos ritmos e melodias populares numa obra da mais requintada fatura, como Bela Bartók. Comparada a semelhante processo, a literatura regionalista nấo ultrapassa a esfera do programa caipira.
Há motivo para invocar o universo da musica ao falarmos deste li vro, náo obstante tăo acentuadamente plastico nas camadas externas. Em profundidade é governado, com eieito, por algunz temas que, uma vez apresentados, săo desenvolvidos, recapitulados, variados, formando o verdadeiro fio condutor de tudo a que se expóe no plano da açăo e da descrişáo, de modo a resultar a integridade quase obsessiva das diretrizes essenciais. Tema do Menino que se desdobra. como da predestinacão, no companheiro Diadorim (muther disfarçada em jagunço, sabemos afinals e decide a carreira do narrador, Riobaldo. Tema do amor coino aspiraçăo e porto de inquietudes, extremamente complexo nas suas três encarnaçōes de pureza de sensualidade e impulsos obscuros: a bem-amada ("minha Otacilia, fina de recanto. em seu realce de mocidade, mimo de alecrim, a firque era clarz, com os othos toro de. la mesma"); o amigo disfarçado ("aquele fino das feiços que eu não podia divulgar, mas lembrava, referido, na fantasia da idéia"). Soponsabilidade, encido ca negada e sentida do nemonio sem duvida o maior personagem do jivro no plano transcendente, como e. no plano fisico, o Sertão, onde o narrador busca as veredas da verdade: "uma receita, a norma dum caminho certo. estreito, de cada tuma pessoa viver". Por estranho que pareça, esta narrativa sertaneja de experiencias profundas Mundo, Diabo e Carne, é sobretudo um livro absorvido por certos pro. blemas, sobretudo por certos proabordado de um angulo gue os exjs. tencialistas chamariam do "ser-no. mundo".

Para conter tanta riqueza plastica e emocional, Guimaräes plastiuniu pitoresco e essencial numa tec. nica narrativa admiravel. marcada pelo vaivém. o parentese, a antecipação, a digressấo, a retornada que ampliam a nossa percepsấo em amplitude e profundidade - para desembocar na linha reta e palpitante da tersa parte final, quando Riobaldo assume o destino nas mãos, disposto a aceitar o bem e o mal. ra fundem-se então numa criadoonde percebemos, emocionados, ses raros momentos em que as, desrealidade particular braslleirassa transiorma em substancia universe perdendo a sua expressso universal, perdendo a sua expressão aullo que, por exemplo, tinha de voluntariamente ingenuo na rapsodia diorir a de Macunaima, para adquirir a soberana maturidade das obras que razem sentir o homem perene.
A.C. $\because 2$

CANDIDO, Antonio. Grande sertão: veredas. O Estado de S. Paulo, Suplemento Literário, n.1, p. 2, 6 out.1956. 


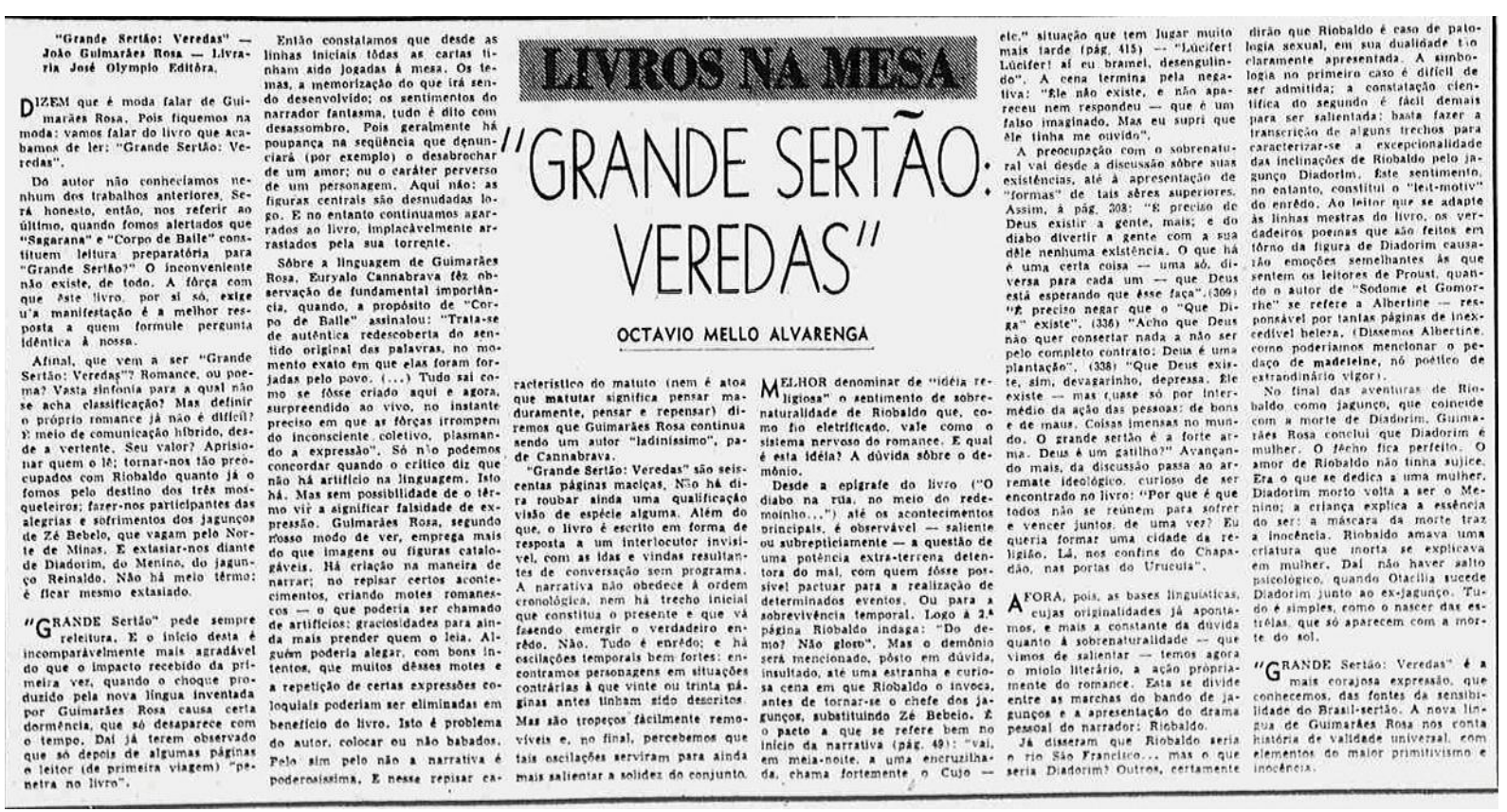

ALVARENGA, Octávio Mello. Grande sertão: veredas. Correio da Manhã, Rio de Janeiro, n. 19.519, p. 9, 10 nov.1956. 